\title{
FROM THE HISTORY OF THE FORMATION OF CRIMINAL INVESTIGATION IN DONBASS (1900-1917)
}

\author{
Victoria K. Groshevaya \\ Academy of Management of the Ministry of Internal Affairs of Russia, Moscow, Russian Federation; \\ Donetsk Academy of Internal Affairs of the Ministry of Internal Affairs of the Donetsk People's Republic, \\ Donetsk, Donetsk People's Republic
}

Introduction: at all stages of national history, the criminal police units occupied and still occupy a dominant place in the system of internal affairs bodies. The appeal to the historical experience of the formation and activities of the detective police as a specialized body of criminal investigation of the police service on the territory of the Donetsk coal basin acquires special scientific and practical relevance, allowing to reveal the prerequisites for the creation of units of this service in the region, analyze their financial and staffing, features of combating crime in the local measurement. The purpose of the article is to study the aspects and patterns of the formation and development of criminal investigation in the early twentieth century. on the territory of Donbass, analysis of the organizational and legal framework for the activities of these units. Methods: the methodological basis of the research is a set of methods of scientific knowledge, including the method of historicism, the method of consistency, the method of analysis and the comparative legal method. Results: the article examines the most important normative legal acts of that time, the provisions of which affect the issues of improving the legal regulation of combating crime, as well as the organization of the work of detective (operational) departments of the internal affairs bodies. The main aspects and patterns of the formation and development of criminal investigation in the territory of Donbass at the beginning of the $20^{\text {th }}$ century are revealed. Conclusions: formation of the criminal investigation service at the beginning of the twentieth century. in the pre-revolutionary Donbass took place in the conditions of a more complicated operational situation, taking into account the specifics of the ongoing socio-economic processes, the features of the industrial development of a large industrial region. On the example of Donbass, the article shows the dependence of the growth of the effectiveness of the fight against crime on the level of legal regulation of these social relations, the successful organization of the work of criminal investigation.

Key words: Donbass, law enforcement activities, crime, disclosure, search, criminal investigation.

Citation. Groshevaya V.K. From the History of the Formation of Criminal Investigation in Donbass (19001917). Legal Concept = Pravovaya paradigma, 2021, vol. 20, no. 2, pp. 121-127. (in Russian). DOI: https://doi.org/ 10.15688/lc.jvolsu.2021.2.16

УДК 351.745.7(477.62)“1900/1917”

Дата поступления статьи: 10.02.2021

ББК 67.401.133.11(4Укр-4Дон)

Дата принятия статьи: 11.03.2021

\section{ИЗ ИСТОРИИ СТАНОВЛЕНИЯ УГОЛОВНОГО СЫСКА В ДОНБАССЕ (1900-1917 гг.)}

\footnotetext{
Виктория Константиновна Грошевая

Академия управления МВД России, г. Москва, Российская Федерация; Донецкая академия внутренних дел Министерства внутренних дел Донецкой Народной Республики, г. Донецк, Донецкая Народная Республика

Введение: на всех этапах отечественной истории подразделения криминальной полиции занимали и занимают доминирующее место в системе органов внутренних дел. Обращение к историческому опыту становления и деятельности сыскной полиции как специализированного органа уголовного сыска полицейской службы на территории Донецкого угольного бассейна приобретает особую научную и практическую
} 


\section{ТЕОРИЯ И ПРАКТИКА ГОСУДАРСТВЕННО-ПРАВОВОГО РАЗВИТИЯ}

актуальность, позволяя раскрыть предпосылки создания в регионе подразделений данной службы, проанализировать их финансовое и кадровое обеспечение, особенности противодействия преступности в локальном измерении. Целью статьи является исследование аспектов и закономерностей становления и развития уголовного сыска в начале XX в. на территории Донбасса, анализ организационно-правовых основ деятельности указанных подразделений. Методы: методологическую основу исследования составляет совокупность методов научного познания, среди которых методы историзма, системности, анализа и сравнительно-правовой метод. Результаты: в статье исследованы важнейшие нормативные правовые акты того времени, положения которых затрагивают вопросы совершенствования правового регулирования борьбы с преступностью, а также организацию работы сыскных (оперативных) подразделений органов внутренних дел. Выявлены основные аспекты и закономерности становления и развития уголовного сыска на территории Донбасса в начале XX века. Выводы: становление службы уголовного сыска в начале XX в. в дореволюционном Донбассе происходило в условиях усложнившейся оперативной обстановки с учетом специфики происходящих социально-экономических процессов, особенностей индустриального развития крупного промышленного региона. На примере Донбасса в статье показана зависимость роста эффективности борьбы с преступностью от уровня правовой урегулированности указанных общественных отношений, успешной организации работы уголовного сыска.

Ключевые слова: Донбасс, правоохранительная деятельность, преступность, раскрытие, розыск, уголовный сыск.

Цитирование. Грошевая В. К. Из истории становления уголовного сыска в Донбассе (1900-1917 гг.) // Legal Concept = Правовая парадигма. - 2021. - Т. 20, № 2. - C. 121-127. - DOI: https://doi.org/10.15688/ lc.jvolsu.2021.2.16

\section{Введение}

История становления сыскной полиции в Российской империи, и в Донецком крае в частности, нашла свое отражение в ряде научных исследований, среди которых следует выделить труды М.Ю. Гутмана, А.Е. Епифанова, С.Н. Жарова, В.И. Кудина, А.Я. Малыгина, Т.Л. Матиенко, Р.С. Мулукаева, С.А. Невского, В.Й. Татаринова и др.

В рамках осуществления общей реформы полиции, связанной с проведением в стране буржуазных реформ после отмены крепостного права в 1861 г., создаются и начинают действовать специализированные сыскные части для оперативного противодействия уголовной преступности. Первое сыскное отделение было создано в 1866 г. в г. Санкт-Петербурге по инициативе градоначальника столицы Ф.Ф. Трепова, который обосновывал необходимость его создания. Одновременно были сформулированы актуальные до настоящего времени важнейшие направления деятельности уголовного сыска в сфере борьбы с преступностью, среди которых: наблюдение за преступниками, выпущенными на свободу, освободившимися из мест заключения; производство дознаний по доносам, заявлениям и анонимкам; оперативный поиск в местах скопления преступного элемента; посещение общественных мест и организация присутствия сотрудников в местах массового скопления населения [8, с. 257]. Указанная модель правоохранительной деятельности, методика ее организации и функционирования показывают преемственность в контексте работы современных оперативных служб.

В начале XX в. осуществление правоохранительной деятельности на территории Донбасса отличалось сложностью и запутанностью организационного взаимодействия подразделений, неопределенностью их функциональных обязанностей, что было обусловлено территориально-административным разделением Донецкого бассейна. Данное положение приводило к дезорганизации взаимодействия между отдельными службами и подразделениями, к разногласиям между руководителями администраций, местных предпринимательских структур, в целом крайне негативно отражаясь на борьбе с общеуголовной преступностью в регионе.

Следует учитывать, что правоохранительная деятельность в Донбассе в исследуемый период имела свою специфику, по-своему отражая глубинный и масштабный характер социально-экономических и культурных изменений в регионе, стремительно превратившемся в крупнейший индустриальный центр империи. В городах и рабочих поселках Дон- 
басса традиционные сословные преграды, морально-этические ценности и нормы подвергались серьезной ревизии, исчезали под воздействием новых реалий социальной практики, порождая предпосылки для преступных проявлений. Среди специфических условий локального характера, которые негативно влияли на криминальную обстановку, следует выделить: 1) высокую плотность и многонациональный состав населения региона; 2) высокий уровень миграционных потоков и значительную подвижность населения; 3) наличие значительного количества временных рабочих и шахтеров, во многом сохранивших связь с деревней; 4) значительную степень концентрации производства и эксплуатации работников; 5) низкий уровень социального обеспечения населения; 6) сложности в идентификации личности правонарушителей и наличие большого количества беглых преступников, следить за паспортным статусом которых было очень сложно; 7) малочисленность полиции, ее зависимость от владельцев промышленных предприятий и шахт.

В конце XIX - начале XX в. мощное промышленное развитие Донбасса сопровождалось значительным ростом преступности. Так, в Бахмутском уезде в 1897 г. было заведено 9057 уголовных дел, а в 1902 г. - 10 606. В начале XX в., особенно в период революции 1905-1907 гг. в России, существенно возросло количество грабежей, краж и разбоев. Хищения и иные преступления против собственности (с удельным весом 60 \%) лидировали в общей массе преступлений на протяжении 1901-1908 годов.

В дореволюционной России полиция, с одной стороны, входила в систему государственных органов (в систему Министерства внутренних дел), а с другой стороны - в значительных объемах финансировалась за счет местного самоуправления (в губерниях, уездах, на казачьих территориях) и получала материальную поддержку со стороны местных предпринимателей. Так, в уездном центре Бахмуте в начале века содержание полиции обходилось городской думе в 4050 рублей в год [10, с. 195-196].

Местное руководство пыталось противодействовать разгулу преступности путем осуществления ряда организационных мероприя- тий, в том числе и за счет увеличения штата полиции, что обусловливало поиск новых источников финансирования. В декриминализации региона были заинтересованы практически все социальные группы населения Донбасса, в том числе и наиболее состоятельная его часть, представленная владельцами заводов и шахт. С другой стороны, «деловая элита» частично содержала полицейский аппарат, способствовала решению вопросов материально-технического обеспечения местных органов правопорядка. Сотрудники полиции на государственном балансе имели доход 19 рублей в месяц, что соответствовало месячному доходу грузчика Новороссийского общества [9, с. 500].

Можно констатировать, что финансирование полицейской службы за счет местных промышленников крайне негативно отражалось на объективности в расследовании преступлений. Для владельцев местных предприятий наиболее важным являлось обеспечение безопасности своей собственности, недопущение преступных посягательств на нее.

Правовая база действий полицейских сыска нуждалась в совершенствовании. В это время выдвигаются различные планы реформирования уголовного розыска, среди которых следует выделить разработанный на основе заимствования немецкого и французского опыта проект по организации сыскных летучих отрядов (бригад). Первый «летучий отряд» был создан в петербургской сыскной полиции в 1902 году. В обязанности отряда входило проведение обходов и облав в наиболее злачных местах (ночлежках, притонах, публичных домах, трактирах), а также поимка преступников и подозреваемых [5, с. 26].

После революции 1905-1907 гг., в процессе проведения Столыпинской аграрной реформы, в России наблюдается ослабление социального контроля, вследствие чего возрастает люмпенизация части сельского населения. Официальные источники в тот период отмечали низкое качество работы полиции по розыскному направлению, что стало очевидным в связи с неспособностью полиции противодействовать возникшим в России волнениям, пополнению недовольными гражданами рядов преступников.

Основным аргументом относительно необходимости обособления специальных под- 


\section{ТЕОРИЯ И ПРАКТИКА ГОСУДАРСТВЕННО-ПРАВОВОГО РАЗВИТИЯ}

разделений уголовного сыска было усиление качества негласной оперативно-розыскной работы как вспомогательной части деятельности по расследованию преступлений в целом. Действенной мерой в борьбе с преступностью стало принятие закона «Об организации сыскной части» в Российской империи от 6 июля 1908 г., в результате чего в городах Российской империи было создано 89 сыскных отделений [7, с. 167-168].

Оперативные подразделения того времени заимствовали опыт Охранного отделения, наработанный за период борьбы против государственных преступлений. Широко использовался опыт филерской школы Е.П. Медникова, в обязанности которой входило проведение наружного наблюдения и негласный сбор информации о людях, представляющих угрозу для государственных устоев. Между тем численность и техническое оснащение Екатеринославского сыскного отделения не соответствовали реалиям криминогенной обстановки. Средств не хватало даже на обеспечение телефонной связи между Бахмутской земской управой и розыскным жандармским пунктом Юзовки [10, с. 196].

В 1907 г. по решению Екатеринославского губернского земского собрания для организации эффективной борьбы с преступностью, а также оказания содействия полиции в рамках расходов, выделявшихся на раскрытие, преследование и поимку преступников, в семи уездах, в том числе Бахмутском, Славяносербском и Мариупольском, были созданы особые сыскные команды. В Екатеринославской губернии, в том числе в трех донецких уездах, сыскные команды функционировали за счет средств, выделяемых местной властью. В то же время попытки создания аналогичных подразделений в соседней Курской губернии успехом не увенчались. В рамках осуществления надзора за деятельностью сыскных команд и расходованием средств на их содержание в уездах проводились неофициальные уездные совещания под руководством предводителя дворянства [11, с. 601].

С созданием сыскных отделений и команд в Донбассе борьба с преступностью приобрела целенаправленный характер. Число правонарушений уменьшилось, уровень раскрываемости был внушителен. В 1909 г. в
Екатеринославской губернии совершено 230 преступлений, из них раскрыто 224; в 1910 г. - 350, раскрыто - 287; в 1911 г. - 193, раскрыто - 169 [7, с. 169]. Основываясь на этих данных, следует сделать вывод, что оперативная работа сыскных отделений привела к снижению общего уровня преступности в Донецком регионе (по подсчетам автора - на 14 \%). При этом работа уголовного сыска, помимо розыска преступников и их задержания, предусматривала осуществление предупреждения и предотвращения преступлений как отдельного направления деятельности.

Опыт Екатеринославских правоохранителей подтвердил необходимость координации действий правоохранителей и преодоления административно-территориальных ограничений. Составители проекта реформы сыскной системы мечтали о создании на базе 8-го делопроизводства Департамента полиции единой централизованной уголовной полиции. До единой имперской реформы дело так и не дошло. Вместо нее была разработана и утверждена «Инструкция чинам розыскных отделений» от 9 августа 1910 г. - документ в значительной степени полезный и своевременный, но не устранивший многочисленные организационные проблемы. В частности, «Инструкцией...» определялись цели сыскной деятельности: «негласное расследование и производство дознаний в виде предупреждения и устранения, разоблачения и преследования преступных деяний общеуголовного характера... систематический надзор за преступными и порочными элементами путем негласной агентуры и наружного наблюдения» [4, с. 62].

Инструкция узаконила специализацию сотрудников сыска по следующим направлениям: 1) убийства, разбои, грабежи, поджоги; 2) кражи и воровские организации; 3) мошенничество и казнокрадство и др. [8, с. 260].

Также инструкция имела «совершенно секретное» приложение, которым регулировалась методика работы с секретными агентами [3, с. 12].

Принятый документ был в значительной степени полезный и своевременный, но не устранял многочисленные организационные проблемы.

В январе 1913 г. на совещании МВД Российской империи, посвященном вопросам 
борьбы с бандитизмом в Екатеринославской губернии, принято решение провести апробацию новой организационной системы уголовного сыска, предусмотренной проектом об учреждении летучих отрядов. Предлагалось упразднить должность сыскного пристава, финансирующуюся за счет средств местных бюджетов. Причиной данного решения послужила их общая деморализация, обусловленная тем, что приставы «издавна получали такие значительные негласные доходы от шахт, заводов и проч., что проявление ими той честной службы... которая служит необходимым залогом успешной деятельности по преследованию преступности всякого рода, ожидать не приходиться» [7, с. 170].

Первая мировая война 1914-1918 гг. внесла серьезные коррективы в дальнейшее реформирование полиции России. Всеобщая воинская мобилизация, введение ограничений на крепкие спиртные напитки, жесткие правовые нормы военного времени и другие факторы, в том числе политические, на первом этапе снизили уровень преступности: в 1912 г. в судах рассматривалось около 900 тыс. дел; за весь 1914 г. - 600 тыс. дел [1, с. 68-69]. Однако очень скоро ситуация кардинально изменилась. Градоначальник Петрограда А.П. Балк обратил внимание на то, что преступность растет и «начинает принимать характер общего бедствия, переживаемого большинством наших городов». В 1916 г. было утверждено положение «Об усилении полиции в 50 губерниях (в том числе в Екатеринославской) и об улучшении служебного и материального положения полицейских чинов». В соответствии с указанным постановлением нагрузка на полицейских снизилась, число обслуживаемых граждан уменьшилось с 500 до 400 жителей города и с 2,5 до 2 тыс. сельчан [2, с. 16].

Донбасс был глубоким тылом воюющей Российской империи, тем не менее лишения войны не обошли Донецкий край. Неизбежное падение уровня жизни, ужесточение условий труда, закрытие предприятий, не имеющих военного значения, милитаризация труда и, самое главное, серьезная нехватка рабочих рук - все это усложнило жизнь в регионе. После мобилизации 1914 г. численность рабочих на заводах уменьшилась на $30 \%$, а шахт - на 50 \%. Ушедших на фронт частично замещали женщины и несовершеннолетние (подростки), однако все же были работы, требовавшие исключительно мужской силы. Крупные промышленники нашли выход из сложившейся ситуации, привлекая к труду специально завезенных в Донбасс с этой целью корейцев и китайцев. Более того, на некоторых предприятиях в качестве рабочей силы использовались военнопленные. В годы войны был введен «сухой закон», и, как следствие, в Донецком крае ускоренными темпами растет самогоноварение и употребление ядовитых спиртовых веществ, что стало дополнительным фактором криминализации общества. Чтобы сохранить подобие криминального благополучия, в Юзовке и Мариуполе под охраной полиции были разрешены «погреба русских виноградных вин», где они продавались на розлив [6, с. 3]. В стране существовала шпиономания, которая очень часто прибавляла бесполезные хлопоты сыскным отделениям и жандармерии.

\section{Выводы}

Становление службы уголовного сыска в начале XX в. в дореволюционном Донбассе происходило в условиях усложнившейся оперативной обстановки с учетом специфики происходящих социально-экономических процессов, особенностей крупного промышленного региона. Развитие сыска, для которого было характерно наличие полуцентрализованного управления и территориального принципа функционирования, являлось отражением процесса реформирования всей системы полиции. Уголовный сыск к тому времени еще не сформировался как самостоятельное обособленное подразделение в системе правоохранительных органов Российской империи. Указанному состоянию способствовала недостаточность средств на содержание и материально-техническое обеспечение подразделений. Кроме того, серьезные коррективы в реформирование полиции России внесла Первая мировая война. Однако во многом эффективное правовое регулирование общественных отношений на примере Донбасса обусловило успех борьбы с преступностью на мест- 


\section{ТЕОРИЯ И ПРАКТИКА ГОСУДАРСТВЕННО-ПРАВОВОГО РАЗВИТИЯ}

ном уровне, улучшило отношения органов уголовного сыска с городскими властями и общественностью.

\section{СПИСОК ЛИТЕРАТУРЫ}

1. Гернет, М. Н. Преступность за границей и в СССР / М. Н. Гернет // Сборник статистических сведений по Союзу ССР. 1918-1923. - М., 1924. С. $66-69$

2. Гутман, М. Ю. Полиция и милиция Петрограда в февральско-мартовские дни 1917 года (к 100летию Февральской революции 1917 года в России) / М. Ю. Гутман, В. И. Кудин // Вестник Санкт-Петербургского университета МВД России. - 2017. № 2. - С. 14-20.

3. Жаров, С. Н. О создании системы правового регулирования политического и уголовного сыска России в XIX - начале XX веков / С. Н. Жаров, Н. С. Спришевский // Вестник Южно-Уральского государственного университета. - 2012. № 20. - C. 9-12.

4. История полиции России. Исторический опыт и основные документы. - М., 2001. - 202 с.

5. Колдаев, В. М. Из истории практической криминалистики в России: применение научных методов работы в розыске и расследовании преступлений: факты, документы, комментарии / В. М. Колдаев. - М. : ЛексЭст, 2005. - 373 с.

6. Мармазов, Р. Юзовская жандармерия. Бытовые зарисовки последних дней империи (19151916 гг.) / Р. Мармазов // Донецкий кряж. - 1996. 7-13 июня.

7. Матиенко, Т. Л. Исторический опыт создания летучих сыскных отрядов в Российской империи / Т. Л. Матиенко // Вестник Московского университета МВД России. - 2008. - № 6. C. $167-170$.

8. Невский, С. А. Создание сыскных отделений в Российской империи / С. А. Невский // Историческая и социально-образовательная мысль. 2012. - № 1 (11). - С. 257-262.

9. Степкин, В. П. Полная история Донецка / В. П. Степкин, В. И. Гергель. - Донецк : Алекс, 2008. $-560 \mathrm{c}$.

10. Татаринов, С. Й. Правоохоронні установи повіту / С. Й. Татаринов, Н. Ю. Тутова // Нариси 3 історії самоврядування в Бахмуті і повіті у XVIIIХХ ст. - Артемівск, 2008. - 227 с.

11. The model of distribution of human and machine labor at intellectual production in industry 4.0 / A. O. Inshakova, E. E. Frolova, E. P. Rusakova, S. I. Kovalev // Journal of Intellectual Capital. - 2020. № 21 (4). - P. 601-622.

\section{REFERENCES}

1. Gernet M.N. Prestupnost za granitsey i v SSSR [Crime Abroad and in the USSR]. Sbornik statysticheskih svedeniy po Soyuzu SSR. 1918-1923 [Collection of Statistical Information on the USSR. 1918-1923]. Moscow, 1924, pp. 66-69.

2. Gutman M.Y., Kudin V.I. Politsya i militsia v Petrograde v fevralsko-martovskie dni 1917 goda (k stoletiuy Fevralskoy revoliutsii 1917 goda v Rossii) [Police and Militia in Petrograd in February-March 1917 (To the $100^{\text {th }}$ Anniversary of the February Revolution in Russia)]. Vestnik Sankt-Peterburgskogo universiteta MVD Rossii, 2017, no. 2, pp. 14-20.

3. Zharov S.N., Sprishevskij N.S. O sozdanii sistemy pravovogo regulirovaniya politicheskogo $\mathrm{i}$ ugolovnogo syska Rossii v XIX - nachale XX vekov [On the Creation of a Legal Regulation System of Political and Criminal Investigation in Russia in the XIX - Early XX Centuries]. Vestnik Yuzhno-Ural'skogo gosudarstvennogo universiteta, 2012, no. 20, pp. 9-12.

4. Istoria politsii Rossii. Istoricheskiy opyt $i$ osnovnye dokumenty [The History of the Russian Police. Historical Experience and Basic Documents]. Moscow, 2001. 202 p.

5. Koldaev V.M. Iz istorii prakticheskoy kriminalistiki $v$ Rossii: primeneniye nauchnih metodov raboty $v$ roziske $i$ rassledovanii prestupleniy: fakty, dokumenty, kommentatii [From the History of Practical Forensics in Russia: The Application of Scientific Methods of Work in the Search and Investigation of Crimes: Facts, Documents, Comments]. Moscow, LexEst Publ., 2005. 373 p.

6. Marmazov R. Yuzovskaya zhandarmeria. Bytovye zarisovki poslednih dney imperii (19151916 gody) [Yuzovskaya Gendarmerie. Household Sketches of the Last Days of the Empire (19151916)]. Donetskiy kryazh [Donetskiy Kryazh], 1996, June 7-13.

7. Matienko T.L. Istoricheskiy opyt sozdaniya letuchih sysknyh otryadov v Rossiyskoy imperii [Historical Experience of Creating Flying Detective Squads in the Russian Empire]. Vestnik Moskovskogo universiteta MVD Rossii [Bulletin of the Moscow University of the Ministry of Internal Affairs of Russia], 2008, no. 6, pp. 167-170.

8. Nevskiy S.A. Sozdaniye sysknyh otdeleniy $\mathrm{v}$ Rossiyskoy imperii [Creation of Detective Department in the Russian Empire]. Istoricheskaya $i$ sotsialno-obrazovatelnaya mysl [Historical and SocioEducational Thought], 2012, no. 1 (11), pp. 257-262.

9. Stepkin V.P., Gergel V.I. Polnaya istoriya Donetska [Full History of Donetsk (1779-1991)]. Donetsk, Alex Publ., 2008. 560 p.

10. Tatarinov C.Y., Tutova N.Y. Pravoohoronni ustanovy povitu [Law Enforcement Establish a 
County]. Narysy z istoriyi samovryaduvannya $v$ Bahmuti I poviti u 18-20 stolittyah [Feature Articles from the History of Self-Production in Bakhmut and the County at the XVIII-XX Centuries]. Artyomovsk, $2008.227 \mathrm{p}$.
11. Inshakova A.O., Frolova E.E., Rusakova E.P., Kovalev S.I. The model of distribution of human and machine labor at intellectual production in industry 4.0. Journal of Intellectual Capital, 2020, no. 21 (4), pp. 601-622.

\section{Information About the Author}

Victoria K. Groshevaya, Doctoral Student, Department of State and Legal Disciplines, Academy of Management of the Ministry of Internal Affairs of Russia, Zoi i Aleksandra Kosmodemyanskikh St, 8, 125993 Moscow, Russian Federation; Candidate of Sciences (Jurisprudence), Associate Professor, ViceRector for Research and International Relations, Donetsk Academy of Internal Affairs of the Ministry of Internal Affairs of the Donetsk People's Republic, Prosp. Zasyadko, 13, 283054 Donetsk, Donetsk People's Republic, vik-groshevaya@mail.ru, https://orcid.org/0000-0002-4554-8657

\section{Информация об авторе}

Виктория Константиновна Грошевая, докторант кафедры государственно-правовых дисциплин, Академия управления МВД России, ул. Зои и Александра Космодемьянских, 8, 125993 г. Москва, Российская Федерация; кандидат юридических наук, доцент, проректор по научной работе и международным связям, Донецкая академия внутренних дел Министерства внутренних дел Донецкой Народной Республики, просп. Засядько, 13, 283054 г. Донецк, Донецкая Народная Республика, vik-groshevaya@mail.ru, https://orcid.org/0000-0002-4554-8657 